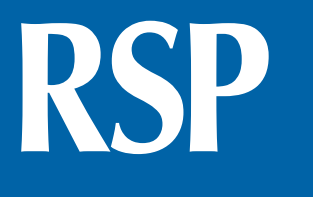

http://www.rsp.fsp.usp.br/
Revista de Saúde Pública

\title{
Population-based seroprevalence of SARS-CoV-2 and the herd immunity threshold in Maranhão
}

\author{
Antônio Augusto Moura da Silva' (iD), Lídio Gonçalves Lima-Neto"l,II ID, Conceição de Maria \\ Pedrozo e Silva de Azevedo ${ }^{\mathrm{IV}, \mathrm{v}}$ (iD, Léa Márcia Melo da Costa ${ }^{\mathrm{vl}}$ (iD, Maylla Luanna Barbosa
} Martins Bragança $^{\mathrm{VII}}$ (iD), Allan Kardec Duailibe Barros Filho ${ }^{\mathrm{VIII}}$ (iD), Bernardo Bastos Wittlin ${ }^{\mathrm{v}, \mathrm{x}}$ (iD), Bruno Feres de Souza ${ }^{\mathrm{x}}$ iD, Bruno Luciano Carneiro Alves de Oliveira ${ }^{\mathrm{IV}}$ (iD, Carolina Abreu de Carvalho $^{\mathrm{xI}}$ (iD, Erika Barbara Abreu Fonseca Thomaz' (iD), Eudes Alves Simões-Neto ${ }^{\mathrm{Ix}, \mathrm{XII}}$ (iD, Jamesson Ferreira Leite Júnior ${ }^{\mathrm{x} I I I}$ (iD, Lécia Maria Sousa Santos Cosme"I (iD, Marcos Adriano Garcia Campos $^{\mathrm{xIV}}$ (D), Rejane Christine de Sousa Queiroz' iD, Sérgio Souza Costa ${ }^{\mathrm{x}}$ iD, Vitória Abreu de Carvalhoxiv (iD, Vanda Maria Ferreira Simões' (iD, Maria Teresa Seabra Soares de Brito e Alves' (iD, Alcione Miranda dos Santos' iD

' Universidade Federal do Maranhão. Departamento de Saúde Pública. São Luís, MA, Brasil

" Secretaria de Saúde do Estado do Maranhão. Laboratório Central do Maranhão. São Luís, MA, Brasil

III Universidade CEUMA. São Luís, MA, Brasil

Iv Universidade Federal do Maranhão. Departamento de Medicina I. São Luís, MA, Brasil

$\checkmark$ Secretaria de Saúde do Estado do Maranhão. Hospital Presidente Vargas. São Luís, MA, Brasil

vı Secretaria de Saúde do Estado do Maranhão. Assessoria. São Luís, MA, Brasil

VII Universidade Federal do Maranhão. Departamento de Ciências Fisiológicas. São Luís, MA, Brasil

VIII Universidade Federal do Maranhão. Departamento de Engenharia Elétrica. São Luís, MA, Brasil

Ix Universidade Federal do Maranhão. Hospital Universitário. São Luís, MA, Brasil

x Universidade Federal do Maranhão. Departamento de Engenharia da Computação. São Luís, MA, Brasil

xI Universidade Federal do Maranhão. Curso de Medicina. Pinheiro, MA, Brasil

xII Secretaria Municipal de Saúde. São Luís, MA, Brasil

xIII Secretaria de Saúde do Estado do Maranhão. Centro de Informações Estratégicas de Vigilância em Saúde. São Luís, MA, Brasil

XIv Universidade Federal do Maranhão. Programa de Pós-Graduação em Saúde Coletiva. São Luís, MA, Brasil

Correspondence:

Antônio Augusto Moura da Silva Universidade Federal do Maranhão

Departamento de Saúde Pública Rua Barão de Itapary, 155

65020-070 São Luís, MA, Brasil

E-mail: aamouradasilva@gmail.com

Received: Oct 23, 2020

Approved: Oct 27,2020

How to cite: Silva AAM, LimaNeto LG, Azevedo CMPS, Costa LMM, Bragança MLBM, BarrosFilho AKD, et al. Population-based seroprevalence of SARS-CoV-2 and the herd immunity threshold in Maranhão. Rev Saude Publica. 2020;54:131.

Copyright: This is an open-access article distributed under the terms of the Creative Commons Attribution License, which permits unrestricted use, distribution, and reproduction in any medium, provided that the original author and source are credited.

\section{ABSTRACT}

OBJECTIVE: To estimate the seroprevalence of SARS-CoV-2 in the state of Maranhão, Brazil.

METHODS: A population-based household survey was performed, from July 27, 2020 to August 8, 2020. The estimates considered clustering, stratification and non-response. Qualitative detection of $\operatorname{IgM}$ and IgG antibodies was performed in a fully-automated Elecsys ${ }^{\circledR}$ Anti-SARS-CoV-2 electrochemiluminescence immunoassay on the Cobas ${ }^{\circledR}$ e601 analyzer (Roche Diagnostics).

RESULTS: In total, 3,156 individuals were interviewed. Seroprevalence of total antibodies against SARS-CoV-2 was 40.4\% (95\%CI35.6-45.3). Population adherence to non-pharmaceutical interventions was higher at the beginning of the pandemic than in the last month. SARS-CoV-2 infection rates were significantly lower among mask wearers and among those who maintained social and physical distancing in the last month compared to their counterparts. Among the infected, 26.0\% were asymptomatic. The infection fatality rate (IFR) was $0.14 \%$, higher for men and older adults. The IFR based on excess deaths was $0.28 \%$. The ratio of estimated infections to reported cases was 22.2 .

CONCLUSIONS: To the best of our knowledge, the seroprevalence of SARS-CoV-2 estimated in this population-based survey is one of the highest reported. The local herd immunity threshold may have been reached or might be reached soon.

DESCRIPTORS: Seroepidemiologic Studies. Coronavirus Infections. Immunity, Herd. Mortality. 


\section{INTRODUCTION}

Brazil is one of the countries most severely affected by the coronavirus disease 2019 (COVID-19) pandemic. By September 21, 2020, 4,558,040 cases were reported, with 137,272 deaths ${ }^{1}$. The national response has been controversial, testing capacity is low, and disagreements among the different levels of government over social distancing measures conveyed contradictory messages to the population. As a middle-income country, Brazil has high poverty rates and an extensive part of its population is engaged in informal activities that face difficulties to make ends meet and to follow stay-at-home measures ${ }^{2}$. As a consequence of all these facts, social distancing has not reached levels sufficient to curb and contain the COVID-19 pandemic ${ }^{3}$.

The state of Maranhão is located in the Northeast region of Brazil and has a population of $7,114,598$ inhabitants in $2020^{4}$, with an area of $329,642 \mathrm{~km}^{2}$, a little larger than that of Italy. It is one of the states in Brazil, where the pandemic gathered speed early. Its first case was reported on March 20, 2020, and by September 21, 2020 the number of deaths reported was 3,664. Deaths peaked in May and decreased thereafter. From May 3, 2020 to May 17, 2020, São Luís Island, where the state capital city is located, was put into lockdown. Reduction of social mobility reached at most $55 \%$ at the end of March and during lockdown at the capital, remaining low (40\%-45\%) during the worst phase of the pandemic. Despite low home quarantine adherence, the number of deaths decreased, and intensive care units occupancy diminished ${ }^{5}$.

Herd immunity threshold to attain control of severe acute respiratory syndrome coronavirus 2 (SARS-CoV-2) is an ongoing debate. Although some consider it to be around $60 \%-70 \%$, using the classical formula $1-1 / \mathrm{R}_{0}$, in which $\mathrm{R}_{0}$ is the basic reproductive number ${ }^{6}$, other reports have proposed that herd immunity could be as low as $10 \%-20 \%^{7}$ or around $43 \%^{8}$, due to the heterogeneity in susceptibility or exposure to infection across population groups $^{7.8}$. However, reported population-based seroprevalences of SARS-CoV-2 were lower than the herd immunity thresholds, ranging from extremely low infections rates, close to $1 \%-3 \%^{9,10}$, to values as high as $14.3 \%$ in Barcelona ${ }^{11}$, Spain, and $22.7 \%$ in New York City ${ }^{12}$. In Brazil, the highest reported population-based seroprevalences were $17.9 \%$, for the São Paulo municipality ${ }^{13}$, and $66 \%$ for Manaus, where herd immunity may have played an important role in stablishing the size of the epidemic ${ }^{14}$.

The infection fatality rate (IFR) and the percentage of asymptomatic infections of SARS-CoV-2 are known with uncertainty. Early reports at the beginning of the pandemic estimated IFR at values between $0.6 \%$ and $1.3 \%^{15,16}$, and considered asymptomatic infections as being highly prevalent ${ }^{15,17}$. Most recent reviews, however, estimated a lower IFR with large variations across sites ${ }^{10,18}$ and a much lower percentage of asymptomatic infections ${ }^{11,19,20}$.

Population-based surveys are necessary to monitor the infection progression, since most cases are undocumented ${ }^{21}$. However, few population-based studies on the prevalence of SARS-CoV-2 have been performed, especially in low and middle-income countries. In this population-based study, we estimated the overall seroprevalence of SARS-CoV-2 using a serum testing electrochemiluminescence immunoassay. Sociodemographic characteristics of the population, self-reported symptoms, adherence to non-pharmaceutical interventions (NPI), use of health services, previous molecular and antibody testing among the infected, and the IFR were also assessed.

\section{METHODS}

\section{Study Design and Participants}

A cross-sectional survey to estimate the seroprevalence of antibodies against SARS-CoV-2 was conducted from July 27, 2020 to August 8, 2020 by population-based household sampling, in cooperation between the Universidade Federal do Maranhão and the Secretaria de Saúde do Estado do Maranhão, Brazil. 
Conglomerate sampling in three stratified stages in four regions was used. The regions were the Island of São Luís, including the state capital, small municipalities ( $<20,000$ inhabitants), medium-sized municipalities (20,000 to 100,000 inhabitants) and large municipalities except for the island (> 100,000 inhabitants). In each stratum, in the first stage, 30 census tracts were selected by systematic sampling. In the second stage, 34 households were selected in each census tract by systematic sampling. In the third stage, an eligible resident (residing for at least six months in the household) aged one year or more was selected by simple random sampling using a table of random numbers.

\section{Data Collection, Instruments, and Variables}

Trained professionals from the municipal and state health departments were responsible for data collection. The starting point (identified with an $\times$ on the map) and the geographic boundaries of each census tracts were identified using a map provided by the Brazilian Institute of Geography and Statistics (IBGE). The first interview was held in the household closest to the starting point of each sector. Then, facing that domicile, the interviewer walked to the left with his/her right shoulder facing the wall/residences. Without including the visited house, the interviewer counted five residences and conducted the next interview in the fifth one. If the selected household was empty at the time or the elected person did not agree to participate in the survey, the next house to the left (neighbor) of the original one was taken as a replacement. If that house was also empty or if the elected person refused to participate the next house to the left was visited. Then the interviewer counted five domiciles and conducted the next interview in the fifth house after the original one. The team always proceeded to the left in relation to the last surveyed domicile and conducted the next interview in the fifth domicile. Non-residential buildings were excluded from the count. After completing the tour on the block, the interviewer facing the last visited domicile continued to the next adjacent block located to the left, always adopting the same strategy.

A questionnaire with closed-ended questions was applied in a face-to-face interview with the individual or his/her legal guardian. The questionnaire was composed of sociodemographic questions, adherence to NPI, self-reported symptoms, and the use of health services. The sociodemographic questions included sex, age group, self-reported skin color/race, head of the household's schooling, monthly family income in Brazilian Reals, and the number of the household residents. Head of the household's schooling was classified according to the International Standard Classification of Education (ISCED) 2011 into early childhood/primary/lower secondary education (levels $0-2$ ), upper secondary/post-secondary non-tertiary education (levels $3-4$ ), and tertiary education and beyond (levels 5-8) ${ }^{22}$. Skin color/race was categorized according to the IBGE and divided into white, brown, or black ${ }^{23}$.

Adherence to NPI at the beginning of the pandemic and in the last month included social distancing (yes, if the person never leaves home or seldom goes out, with a maximum of one outing every fifteen days, and no otherwise), wearing of face masks (yes, if the individual uses a mask on all exits and does not remove or seldom removes the mask from the face, and no otherwise), hand hygiene (yes, if the person sanitizes the hands more than six times per turn with soap or an alcohol gel, and no otherwise), and physical distancing (yes, if the individual never or hardly ever comes within $1.5 \mathrm{~m}$ of other people, and no otherwise).

A self-reported symptom rating, adapted from Pollán et al. $(2020)^{11}$ was used and the persons were classified into asymptomatic; oligosymptomatic: the presence of one to two symptoms without anosmia/hyposmia or ageusia/dysgeusia; and symptomatic: anosmia/hyposmia or ageusia/dysgeusia or more than two symptoms including fever, chills, sore throat, cough, dyspnea, diarrhea, nausea/vomiting, headache, fatigue, and myalgia.

Questions on the use of health services included if the individual looked for health services, received care when seeking health services, was hospitalized for over 24 hours, received a 
medical diagnosis of suspected COVID-19, performed RT-PCR for SARS-CoV-2, and performed an antibody test- point-of-care/serology for SARS-CoV-2.

Data were abstracted into the Epicollect5 Data Collection mobile application.

\section{SARS-CoV-2 Antibodies Detection}

For the qualitative determination of antibodies against SARS-CoV-2, $5.0 \mathrm{ml}$ of whole blood was collected, and after centrifugation at $1800 \mathrm{~g}$ for $15 \mathrm{~min}$, the serum was obtained. Then, a highly sensitive and specific sandwich electrochemiluminescence immunoassay (Elecsys ${ }^{\circledR}$ Anti-SARS-CoV-2 assay, Roche Diagnostics) was used to detect IgM and IgG antibodies against the SARS-CoV-2 nucleocapsid antigen according to the manufacturer's instruction using a fully automated Cobas ${ }^{\circledR}$ e601 immunoassay analyzer (Roche Diagnostics) ${ }^{24}$.

\section{Sample Size Calculation}

The formula used to determine the sample size in each stratum was given by

$$
n=\frac{N}{N-1} \times P \times Q \times \frac{1}{C V^{2} \times P^{2}+\frac{P \times Q}{N-1}}
$$

$\mathrm{N}$ being the population size in each stratum; $\mathrm{P}$ the expected prevalence in the stratum; $\mathrm{Q}=1-\mathrm{P}$; and CV the coefficient of variation of the prevalence estimates within the stratum. In each stratum, the expected prevalence of infection was $20 \%$, and the coefficient of variation was $10 \%$. For the final estimate, a design effect of 2 was added. Thus, the minimum number of individuals per stratum was 800 , totaling 3,200 individuals to compose the sample. Predicting losses, the sample size was increased by $25 \%$ resulting in 4,000 observations.

\section{Statistical Analysis}

The basic sample weight of each selected unit (census sector, household, and individual) was estimated separately for each stratum, considering the inverse of the selection probability according to the sampling plan specified for the study.

The probability of selection of the census sector " $j$ " in each stratum " $i$ " of the sample is given by $30 / \mathrm{S}_{\mathrm{i}}$, in which " $\mathrm{S}_{\mathrm{i}}$ " is the number of census sectors of the stratum "i" in the population and the probability of the domicile of the census sector " $j$ " of the stratum " $i$ " being selected was obtained from the following expression: $34 / \mathrm{D}_{\mathrm{ij}}$, in which " $\mathrm{D}_{\mathrm{ij}}$ " is the number of domiciles in sector " $j$ " of the stratum "i" in the population. The probability of each resident in the selected household was given by $1 /$ (number of residents in the household). The number of sectors and domiciles was obtained from the 2010 Census of the IBGE.

Since losses, refusals, and non-responses occurred, the response rate in each stratum was also estimated. Considering that there were three stages, the final weight was obtained by the product of the basic weight in each stage and the response rate.

All analyses were performed using R version 4.0.2. Weighting factors, clustering, and stratification were incorporated into the analyses via the $R$ survey package. Prevalence and $95 \%$ confidence interval (95\%CI) of SARS-CoV-2 infection was obtained according to the sociodemographic characteristics, adherence to NPI, self-reported symptoms, and the use of health services. The chi-square test, considering the study design, was used to compare the prevalence between groups. The McNemar test was used to compare adherence to NPI over time.

The overall and sex- and age-specific IFR were estimated by dividing the estimated number of deaths by the estimated proportion of infections obtained by the serological survey multiplied by the stratified age and sex population estimates ${ }^{4}$. The number of deaths that occurred up to August 8, 2020 was abstracted from official sources ${ }^{5}$. The number of deaths occurring daily was estimated using Nowcasting by Bayesian Smoothing (NobBS), to consider reporting delays. This procedure incorporates uncertainty both in the delay distribution and in the 
evolution of the pandemic curve over time, resulting in smooth, time-correlated estimates of the number of deaths ${ }^{25}$. Simulations were conducted using the NobBS R package, with a negative binomial model with an adaptation phase of 10,000 iterations and a burn-in of 10,000 iterations for estimating deaths in the state of Maranhão, and the same parameters with 5,000 iterations for the São Luís Island. Furthermore, since there is underascertainment of deaths due to COVID-19, IFR was also estimated considering excess mortality due to all natural causes. Excess deaths were abstracted from the Panel to analyze the excess mortality from natural causes in Brazil in $2020^{26}$. Data on excess mortality is only available stratified by sex and two age groups ( $<60$ and $\geq 60$ years $)^{27}$. The $95 \%$ confidence intervals for the IFR were based on delta methods accounting for the binomial variance in the numerator (number of deaths) and the estimated variance, considering the complex sampling design in the denominator (number of infections) ${ }^{28}$.

\section{Ethical Approval}

Ethical approval was obtained from the Research Ethics Committee of the Carlos Macieira Hospital of the Maranhão State Health Secretariat under CAAE number 34708620.2.0000.8907. An informed consent form was provided by the participants or the parents/legal guardians.

\section{RESULTS}

A total of 3,289 individuals (80.6\%) agreed to participate in our study. After the exclusion of samples with insufficient material or hemolyzed samples, and cases, in which it was not possible to link the result of the examination with the person, 3,156 participants had their blood samples analyzed (77.4\%). Comparing the sampling with the population distribution (age and sex estimates for 2020), men and people of working age were underrepresented in the sample.

Seroprevalence of total antibodies against SARS-CoV-2 was 40.4\% (95\%CI 35.6-45.3) in the state of Maranhão, Brazil. Seroprevalence varied by region, from $20.0 \%$ in small municipalities with $<20,000$ inhabitants, reaching $47.6 \%$ in medium-sized municipalities from 20,000 to 100,000 inhabitants $(p=0.006)$. Seroprevalence in the São Luís Island, including the capital city, was $38.9 \%$. There were no significant differences in the prevalence according to the sex or age group (Table 1).

White people had a lower point prevalence (20.0\%) when compared with both brown (41.3\%) and black people (49.2\%), but of borderline significance (between 0.05 and 0.10 ). Persons with tertiary education had a lower prevalence of infection (27.5\%) than their counterparts $(\mathrm{p}=0.011)$. Although point prevalence was lower among those with a monthly family income above 3,000 Brazilian Reals, the difference did not reach a significant level. Infection rates were higher among households with three dwellers $(44.9 \%)(p=0.028)$ (Table 1).

Population adherence to NPI to contain the COVID-19 pandemic were mostly higher at the beginning of the pandemic than in the last month. Social distancing decreased from $52.7 \%$ to $37.4 \%$ ( $p<0.001)$. The percentage of wearing a face mask decreased from $61.4 \%$ to $55.5 \%$ $(\mathrm{p}<0.001)$. Differences in infection rates between those that maintained social distancing and those that did not were evident both at the beginning of the pandemic (36.4\% vs $45.0 \%$, $\mathrm{p}=0.020)$ and in the last month ( $34.0 \%$ vs $44.3 \%, \mathrm{P}=0.015)$. SARS-CoV-2 infection rates were significantly lower in the last month among mask wearers and those that maintained a distance of at least $1.5 \mathrm{~m}$ from other people compared to their counterparts ( $\mathrm{p}=0.036$ for mask-wearing and $\mathrm{p}=0.030$ for physical distancing) (Table 2).

Differences in the self-reporting symptoms were highly significant comparing those with and without antibodies to SARS-CoV-2. Among the infected, $62.2 \%$ had more than three symptoms, whereas $26.0 \%$ were asymptomatic and, $11.8 \%$ reported only one or two symptoms (oligosymptomatic). The predominant symptoms among those who tested positive for SARS-CoV-2 were anosmia/hyposmia (49.5\%), ageusia/dysgeusia (47.7\%), fever (45.6\%), headache (45.4\%), myalgia (43.6\%), and fatigue (41.1\%) (Table 3). 
Table 1. Prevalence of antibodies against SARS-CoV-2 by region, sex, age group, race, schooling, family income and number of residents, state of Maranhão, Brazil, 2020

\begin{tabular}{|c|c|c|c|c|c|c|}
\hline Variables & $\mathbf{n}$ & $\%$ weighted & $\begin{array}{c}\text { Population } \\
\text { distribution (\%) }\end{array}$ & f infected & $\begin{array}{c}\% \text { infected weighted } \\
\qquad(95 \% \mathrm{CI})\end{array}$ & p \\
\hline Total & 3156 & 100.0 & 100.0 & 1167 & $40.4(35.6-45.3)$ & \\
\hline Region & & & & & & 0.006 \\
\hline São Luís Island including the capital & 737 & 25.5 & 20.2 & 349 & $38.9(24.5-53.2)$ & \\
\hline Municipalities with $<20,000$ inhabitants & 754 & 20.0 & 21.4 & 215 & $31.0(24.3-37.8)$ & \\
\hline Municipalities with 20,000 to 100,000 inhabitants & 839 & 41.6 & 45.1 & 346 & $47.6(42.0-53.1)$ & \\
\hline Municipalities with $>100,000$ inhabitants & 826 & 12.9 & 13.2 & 257 & $35.2(26.1-44.3)$ & \\
\hline Sex & & & & & & 0.134 \\
\hline Male & 1200 & 37.1 & 49.1 & 426 & $37.2(31.8-42.6)$ & \\
\hline Female & 1956 & 62.9 & 50.9 & 741 & $42.4(36.1-48.6)$ & \\
\hline Age group (years) ${ }^{\mathrm{a}}$ & & & & & & 0.230 \\
\hline $1-9$ & 124 & 5.2 & 16.5 & 49 & $42.6(33.8-51.3)$ & \\
\hline $10-19$ & 330 & 14.7 & 18.6 & 125 & $43.0(33.5-52.4)$ & \\
\hline $20-29$ & 427 & 12.5 & 18.0 & 184 & $49.2(41.1-57.3)$ & \\
\hline $30-39$ & 475 & 15.0 & 16.0 & 170 & $44.4(37.4-51.4)$ & \\
\hline $40-49$ & 502 & 16.3 & 12.0 & 191 & $32.2(23.4-41.0)$ & \\
\hline $50-59$ & 501 & 14.6 & 8.5 & 168 & $39.1(32.1-46.1)$ & \\
\hline $60-69$ & 409 & 11.7 & 5.7 & 144 & $40.3(29.1-51.4)$ & \\
\hline$\geq 70$ & 386 & 9.8 & 4.8 & 136 & $34.3(25.7-42.9)$ & \\
\hline Self-reported skin color/race ${ }^{b}$ & & & & & & 0.080 \\
\hline White & 590 & 20.0 & - & 200 & $32.2(20.1-44.4)$ & \\
\hline Brown & 2100 & 67.4 & - & 767 & $41.3(37.1-45.4)$ & \\
\hline Black & 396 & 12.6 & - & 177 & $49.1(42.3-55.9)$ & \\
\hline Head of the household's schooling (years)* & & & & & & 0.011 \\
\hline Primary/Lower secondary & 1369 & 37.7 & - & 487 & $40.9(35.4-46.4)$ & \\
\hline Upper secondary & 1251 & 41.9 & - & 512 & $46.2(41.3-51.2)$ & \\
\hline Tertiary & 517 & 20.4 & - & 161 & $27.5(16.9-38.1)$ & \\
\hline Monthly family income (Brazilian Real) ${ }^{\mathrm{a}, \mathrm{c}}$ & & & & & & 0.101 \\
\hline$<1000$ & 607 & 17.7 & - & 222 & $40.8(34.6-46.9)$ & \\
\hline $1000 \mathrm{a}<2000$ & 1405 & 42.5 & - & 540 & $45.9(41.0-50.9)$ & \\
\hline $2000 \mathrm{a}<3000$ & 617 & 20.8 & - & 243 & $42.9(35.7-50.2)$ & \\
\hline$>3000$ & 493 & 19.0 & - & 155 & $27.9(17.0-38.9)$ & \\
\hline Number of residents & & & & & & 0.028 \\
\hline 1 & 386 & 3.9 & - & 122 & $35.4(27.2-43.6)$ & \\
\hline 2 & 840 & 15.7 & - & 302 & $37.7(32.0-43.5)$ & \\
\hline 3 & 739 & 21.2 & - & 297 & $44.9(40.0-49.8)$ & \\
\hline 4 & 628 & 28.0 & - & 234 & $38.8(29.0-48.5)$ & \\
\hline$\geq 5$ & 563 & 31.2 & - & 212 & $40.9(33.5-48.3)$ & \\
\hline
\end{tabular}

95\%Cl: 95\% confidence interval; SARS-CoV-2: severe acute respiratory syndrome coronavirus 2.

a Numbers did not add up to total because of missing values.

${ }^{b}$ Yellow and indigenous were excluded because they were too few for a meaningful analysis.

c 1 Brazilian Real (R\$) is equivalent to approximately US $\$ 5.60$ US dollars.

Among the infected, $27.6 \%$ sought medical care and most received it. A small minority (1.9\%) was hospitalized for over 24 hours, $13.3 \%$ were told they were suspected of having COVID-19, 4.3\% performed an RT-PCR for SARS-CoV-2, and 13.5\% performed a point of care test/serology for SARS-CoV-2 (Table 4).

The IFR was $0.14 \%$ for the state of Maranhão, and $0.28 \%$ for the São Luís Island, considering reporting delays by NobBS. IFR was higher for men and older adults (Table 5). The estimate doubled to $0.28 \%$, using data on excess mortality (Table 6). The case reporting rate was 4.5\% for the state of Maranhão, and 3.4\% for the São Luís Island, resulting in a ratio of the estimated infection to the reported cases as 22.2 for the state of Maranhão, and 29.9 for the São Luís Island (data not shown). 
Table 2. Prevalence of antibodies against SARS-CoV-2 according to adherence to non-pharmaceutical interventions at the beginning of the pandemic and in the last month, state of Maranhão, Brazil, 2020.

\begin{tabular}{|c|c|c|c|c|c|}
\hline Non-pharmaceutical interventions & $\mathbf{n}$ & $\%$ weighted & f infected & $\begin{array}{c}\% \text { infected weighted } \\
(95 \% \mathrm{Cl})\end{array}$ & p \\
\hline \multicolumn{6}{|l|}{ At the beginning of the pandemic } \\
\hline Social distancing & & & & & 0.020 \\
\hline No & 1392 & 47.3 & 557 & $45.0(39.3-50.6)$ & \\
\hline$Y \mathrm{~S}^{\mathrm{a}}$ & 1764 & 52.7 & 610 & $36.4(30.6-42.2)$ & \\
\hline Wearing of face masks & & & & & 0.395 \\
\hline No & 1153 & 38.6 & 423 & $42.3(35.8-48.8)$ & \\
\hline Yes $^{\mathrm{b}}$ & 2003 & 61.4 & 744 & $39.3(33.7-44.8)$ & \\
\hline Hand hygiene & & & & & 0.285 \\
\hline No & 1455 & 47.9 & 554 & $42.7(36.9-48.4)$ & \\
\hline$Y \mathrm{~S}^{\mathrm{c}}$ & 1701 & 52.1 & 613 & $38.4(31.9-44.9)$ & \\
\hline Physical distancing & & & & & 0.065 \\
\hline No & 1548 & 52.2 & 602 & $43.5(37.6-49.4)$ & \\
\hline$Y_{e s}{ }^{d}$ & 1608 & 47.8 & 565 & $37.1(31.4-42.8)$ & \\
\hline \multicolumn{6}{|l|}{ Last month } \\
\hline Social distancing & & & & & 0.015 \\
\hline No & 1875 & 62.6 & 757 & $44.3(39.6-49.0)$ & \\
\hline$Y \mathrm{~S}^{\mathrm{a}}$ & 1281 & 37.4 & 410 & $34.0(26.5-41.4)$ & \\
\hline Wearing of face masks & & & & & 0.036 \\
\hline No & 1310 & 44.5 & 517 & $45.9(40.6-51.3)$ & \\
\hline Yes $^{b}$ & 1846 & 55.5 & 650 & $36.0(29.1-43.0)$ & \\
\hline Hand hygiene & & & & & 0.095 \\
\hline No & 1557 & 51.6 & 612 & $44.4(39.1-49.7)$ & \\
\hline Yes $^{c}$ & 1599 & 48.4 & 555 & $36.2(28.7-43.8)$ & \\
\hline Physical distancing & & & & & 0.030 \\
\hline No & 1817 & 61.0 & 710 & $43.3(38.0-48.6)$ & \\
\hline Yes $^{d}$ & 1339 & 39.0 & 457 & $35.9(29.7-42.2)$ & \\
\hline
\end{tabular}

95\%Cl: 95\% confidence interval; SARS-CoV-2: severe acute respiratory syndrome coronavirus 2.

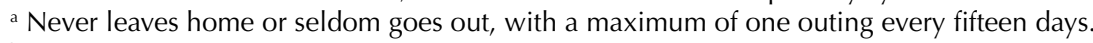

${ }^{b}$ Uses mask on all exits and does not remove or seldom removes the mask from the face.

${ }^{\mathrm{c}}$ Sanitizes the hands $\geq 6$ times per turn (morning, afternoon, and night) with soap or alcohol gel.

${ }^{\mathrm{d}}$ Never or hardly ever comes within $1.5 \mathrm{~m}$ of other people.

Table 3. Reported symptoms of SARS-CoV-2 infection, state of Maranhão, Brazil, 2020.

\begin{tabular}{|c|c|c|c|c|c|}
\hline \multirow{2}{*}{ Variables } & \multicolumn{2}{|c|}{ Non-infected $(n=1,989)$} & \multicolumn{2}{|c|}{ Infected $(n=1,167)$} & \multirow{2}{*}{$\mathbf{p}$} \\
\hline & $\mathbf{n}$ & $\%$ weighted $(95 \% \mathrm{Cl})$ & $\mathbf{n}$ & $\%$ weighted $(95 \% \mathrm{Cl})$ & \\
\hline Self-reported symptom ratinga & & & & & $<0.001$ \\
\hline Asymptomatic & 1104 & $52.1(47.3-56.9)$ & 320 & $26.0(21.0-31.0)$ & \\
\hline Oligosymptomatic ( 1 to 2 symptoms) & 427 & $22.8(18.8-26.7)$ & 134 & $11.8(8.9-14.6)$ & \\
\hline Symptomatic ( $\geq 3$ symptoms) & 458 & $25.2(21.8-28.5)$ & 713 & $62.2(56.2-68.3)$ & \\
\hline \multicolumn{6}{|l|}{ Self-reported symptoms } \\
\hline Fever & 296 & $16.7(13.1-20.4)$ & 494 & $45.6(39.9-51.3)$ & $<0.001$ \\
\hline Shivers & 253 & $13.7(9.9-17.6)$ & 379 & $34.3(29.5-39.2)$ & $<0.001$ \\
\hline Sore throat & 345 & $18.3(14.7-22.0)$ & 378 & $34.5(30.1-39.0)$ & $<0.001$ \\
\hline Cough & 356 & $17.6(13.7-21.5)$ & 369 & $33.1(29.7-36.5)$ & $<0.001$ \\
\hline Dyspnoea & 184 & $10.9(8.4-13.4)$ & 209 & $18.6(15.0-22.2)$ & 0.001 \\
\hline Runny nose & 370 & $19.2(16.0-22.3)$ & 364 & $32.2(28.0-36.5)$ & $<0.001$ \\
\hline Palpitations & 204 & $9.5(7.1-11.9)$ & 178 & $15.6(12.1-19.2)$ & $<0.001$ \\
\hline Anosmia/Hyposmia & 117 & $7.3(5.0-9.6)$ & 547 & $49.5(42.5-56.5)$ & $<0.001$ \\
\hline Ageusia/Dysgeusia & 133 & $8.2(5.8-10.5)$ & 535 & $47.7(40.4-54.9)$ & $<0.001$ \\
\hline Diarrhoea & 186 & $8.9(6.5-11.2)$ & 210 & $18.1(15.1-21.2)$ & $<0.001$ \\
\hline Nausea/vomiting & 146 & $7.2(5.2-9.2)$ & 177 & $15.1(12.0-18.2)$ & $<0.001$ \\
\hline Headache & 509 & $27.5(22.7-32.2)$ & 491 & $45.4(38.7-52.0)$ & $<0.001$ \\
\hline Abdominal pain & 201 & $10.8(7.7-13.9)$ & 196 & $19.8(14.5-25.1)$ & 0.009 \\
\hline Myalgia & 368 & $17.9(14.0-21.8)$ & 485 & $43.6(36.8-50.3)$ & $<0.001$ \\
\hline Fatigue & 333 & $17.1(13.0-21.3)$ & 449 & $41.1(34.5-47.7)$ & $<0.001$ \\
\hline Loss of appetite & 217 & $11.1(8.2-14.0)$ & 396 & $35.2(29.2-41.2)$ & $<0.001$ \\
\hline
\end{tabular}

95\%Cl: 95\% confidence interval; SARS-CoV-2: severe acute respiratory syndrome coronavirus 2.

a Asymptomatic: no symptoms; oligosymptomatic: presence of 1 to 2 symptoms without anosmia/hyposmia or ageusia/dysgeusia; symptomatic: anosmia/hyposmia or ageusia/dysgeusia or more than 2 symptoms including fever, chills, sore throat, cough, dyspnea, diarrhea, nausea/vomiting, headache, fatigue, and myalgia. 
Table 4. Use of health services by individuals with SARS-CoV-2 antibodies, state of Maranhão, Brazil, 2020.

\begin{tabular}{lccc}
\hline Variables & $\mathbf{n}$ & $\%$ & $\mathbf{9 5} \% \mathbf{C l}$ \\
\hline Looked for health service & & & \\
$\quad$ No & 888 & 72.4 & $64.6-80.3$ \\
$\quad$ Yes & 279 & 27.6 & $19.7-35.4$ \\
Received care when sought health service & & & \\
$\quad$ Yes & 239 & 19.0 & $14.9-23.0$ \\
$\quad$ No & 40 & 8.6 & $0.0-18.1$ \\
$\quad$ Did not look for health service & 888 & 72.4 & $64.6-80.3$ \\
Hospitalized for over 24 hours & & & \\
$\quad$ No & 1148 & 98.1 & $96.9-99.2$ \\
$\quad$ Yes & 19 & 1.9 & $0.8-3.1$ \\
Received a medical diagnosis of suspected COVID-19 & 1014 & 86.7 & $83.1-90.2$ \\
$\quad$ No & 153 & 13.3 & $9.8-16.9$ \\
$\quad$ Yes & & & \\
Performed RT-PCR for SARS-CoV-2 & 1123 & 95.7 & $93.5-98.0$ \\
$\quad$ No & 44 & 4.3 & $2.0-6.5$ \\
$\quad$ Yes & & & \\
Performed antibody test (point-of-care/serology) for SARS-CoV-2 & 1019 & 86.5 & $82.8-90.1$ \\
$\quad$ No & 148 & 13.5 & $9.9-17.2$ \\
$\quad$ Yes & 1167 & 100.0 & \\
\hline Total
\end{tabular}

95\%Cl: 95\% confidence interval; SARS-CoV-2: severe acute respiratory syndrome coronavirus 2.

Table 5. Estimated number of infections, deaths, and infection fatality rates of SARS-CoV-2 by sex and age groups, state of Maranhão and São Luís island, Brazil, 2020.

\begin{tabular}{|c|c|c|c|c|}
\hline Sex & Age Group, years & $\begin{array}{c}\text { Estimated number } \\
\text { of infections }\end{array}$ & $\begin{array}{c}\text { Number of deaths } \\
\text { (estimated by nowcasting) }\end{array}$ & $\begin{array}{l}\text { Infection fatality rate, } \\
\%(95 \% \mathrm{CI})\end{array}$ \\
\hline \multicolumn{5}{|l|}{ Male } \\
\hline & $0-9$ & 274,241 & 8 & $0.00(0.00-0.01)$ \\
\hline & $10-19$ & 236,559 & 12 & $0.00(0.00-0.01)$ \\
\hline & $20-29$ & 303,111 & 21 & $0.01(0.00-0.01)$ \\
\hline & $30-39$ & 198,478 & 76 & $0.04(0.03-0.05)$ \\
\hline & $40-49$ & 100,908 & 150 & $0.15(0.10-0.21)$ \\
\hline & $50-59$ & 101,695 & 274 & $0.27(0.18-0.40)$ \\
\hline & $60-69$ & 64,637 & 584 & $0.90(0.68-1.20)$ \\
\hline & $\geq 70$ & 67,000 & 1381 & $2.06(1.56-2.72)$ \\
\hline & Total & $1,299,992$ & 2506 & $0.19(0.17-0.22)$ \\
\hline \multicolumn{5}{|l|}{ Female } \\
\hline & $0-9$ & 228,212 & 14 & $0.01(0.00-0.01)$ \\
\hline & $10-19$ & 323,171 & 5 & $0.00(0.00-0.00)$ \\
\hline & $20-29$ & 320,049 & 16 & $0.01(0.00-0.01)$ \\
\hline & $30-39$ & 282,436 & 56 & $0.02(0.01-0.03)$ \\
\hline & $40-49$ & 155,868 & 81 & $0.05(0.04-0.08)$ \\
\hline & $50-59$ & 132,770 & 163 & $0.12(0.09-0.16)$ \\
\hline & $60-69$ & 94,033 & 345 & $0.37(0.26-0.52)$ \\
\hline & $\geq 70$ & 48,838 & 898 & $1.84(1.25-2.69)$ \\
\hline & Total & $1,533,005$ & 1579 & $0.10(0.09-0.12)$ \\
\hline \multicolumn{5}{|l|}{ Overall } \\
\hline & $0-9$ & 500,448 & 22 & $0.00(0.00-0.01)$ \\
\hline & $10-19$ & 567,266 & 16 & $0.00(0.00-0.00)$ \\
\hline & $20-29$ & 628,088 & 37 & $0.01(0.00-0.01)$ \\
\hline & $30-39$ & 505,975 & 132 & $0.03(0.02-0.03)$ \\
\hline & $40-49$ & 275,270 & 231 & $0.08(0.06-0.11)$ \\
\hline & $50-59$ & 237,395 & 437 & $0.18(0.15-0.22)$ \\
\hline & $60-69$ & 162,429 & 930 & $0.57(0.43-0.76)$ \\
\hline & $\geq 70$ & 116,065 & 2279 & $1.96(1.53-2.52)$ \\
\hline & Total & $2,877,454$ & 4085 & $0.14(0.13-0.16)$ \\
\hline \multicolumn{5}{|c|}{ São Luís Island } \\
\hline Overall & Total & 556,611 & 1544 & $0.28(0.19-0.40)$ \\
\hline
\end{tabular}

IFR: infection fatality rate; SARS-CoV-2: severe acute respiratory syndrome coronavirus 2. 
Table 6. Estimated number of infections, excess deaths, and infection fatality rates of SARS-CoV-2 by sex and age groups, state of Maranhão, Brazil, 2020.

\begin{tabular}{|c|c|c|c|c|c|}
\hline Sex & $\begin{array}{l}\text { Age } \\
\text { Group, } \\
\text { years }\end{array}$ & $\begin{array}{c}\text { SARS-CoV-2 } \\
\text { seroprevalence, \% } \\
(95 \% \mathrm{CI})\end{array}$ & $\begin{array}{l}\text { Estimated } \\
\text { number of } \\
\text { infections }\end{array}$ & $\begin{array}{l}\text { Number of deaths (estimate } \\
\text { based on excess deaths due } \\
\text { to natural causes) }\end{array}$ & $\begin{array}{l}\text { Infection fatality rate } \\
\%(95 \% \mathrm{CI})\end{array}$ \\
\hline \multicolumn{6}{|c|}{ Male } \\
\hline & $0-59$ & $36.38(30.54-42.22)$ & $1,149,733$ & 1366 & $0.12(0.10-0.14)$ \\
\hline & $\geq 60$ & $39.85(32.74-46.95)$ & 133,937 & 3903 & $2.91(2.43-3.49)$ \\
\hline & Total & $37.18(31.81-42.55)$ & $1,299,992$ & 5270 & $0.41(0.35-0.47)$ \\
\hline \multicolumn{6}{|c|}{ Female } \\
\hline & $0-59$ & $44.05(38.71-49.40)$ & $1,415,266$ & 563 & $0.04(0.03-0.05)$ \\
\hline & $\geq 60$ & $36.02(24.46-47.58)$ & 146,117 & 2278 & $1.56(1.13-2.15)$ \\
\hline & Total & $42.37(36.11-48.63)$ & $1,533,005$ & 2840 & $0.19(0.16-0.22)$ \\
\hline \multicolumn{6}{|c|}{ Overall } \\
\hline & $0-59$ & $41.26(36.84-45.69)$ & $2,629,556$ & 1929 & $0.07(0.07-0.08)$ \\
\hline & $\geq 60$ & $37.54(29.24-45.85)$ & 278,482 & 6181 & $2.22(1.78-2.77)$ \\
\hline & Total & $40.44(35.57-45.32)$ & $2,877,454$ & 8110 & $0.28(0.25-0.32)$ \\
\hline
\end{tabular}

IFR: infection fatality rate; SARS-CoV-2: severe acute respiratory syndrome coronavirus 2.

a Fonte: Conselho Nacional de Secretários de Saúde. Painel de análise do excesso de mortalidade por causas naturais no Brasil em 2020. Brasília, DF: CONASS; 2020 [cited 2020 Sept 21]. Available from: https://www. conass.org.br/indicadores-de-obitos-por-causas-naturais/

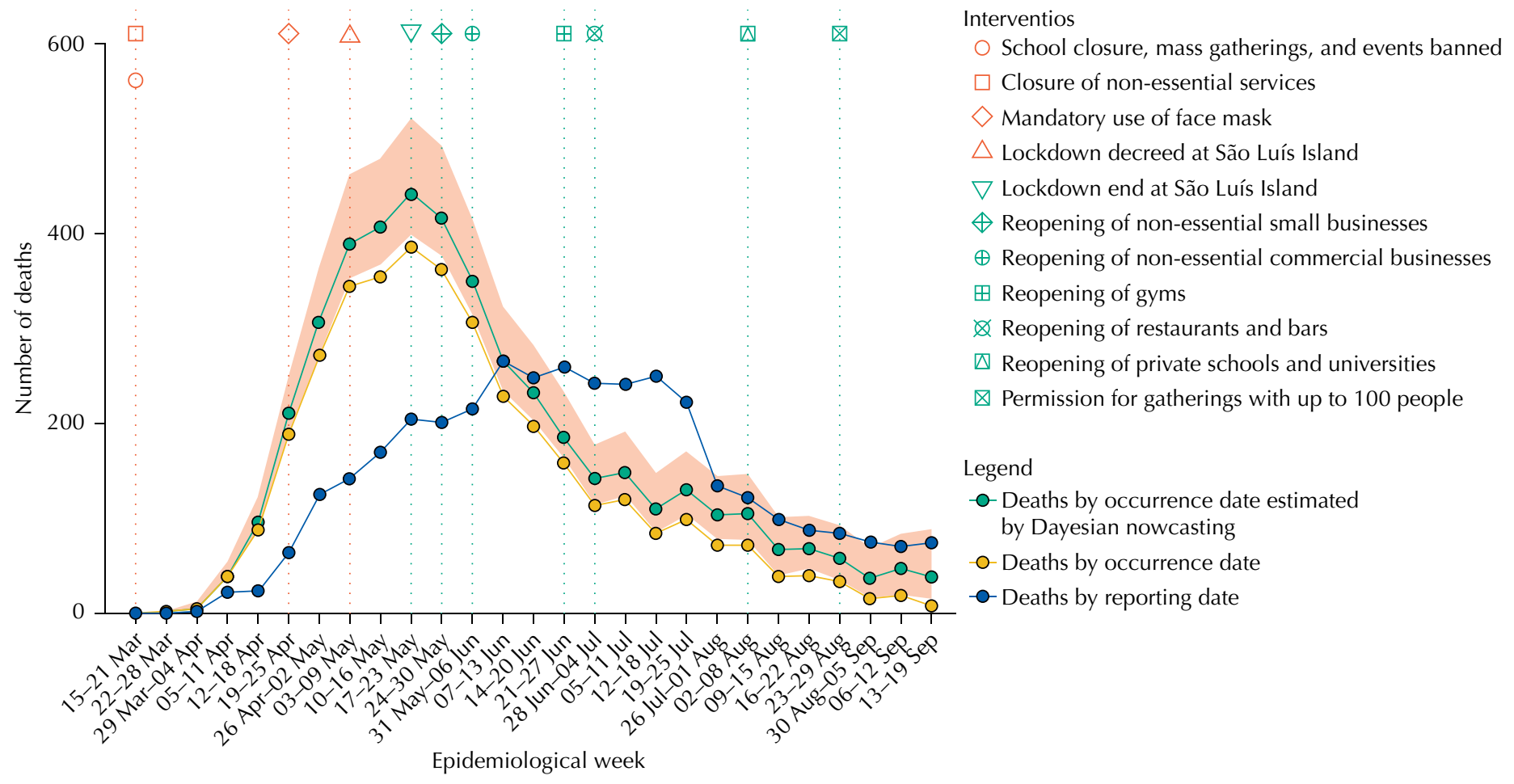

Figure 1. Weekly number of deaths by occurrence and reporting date, and estimated by Bayesian nowcasting from March 15 to September 19, state of Maranhão, Brazil, 2020.

Figure 1 shows dates of introduction of compulsory NPI, the weekly number of deaths by dates of occurrence and reporting and estimates of the weekly number of deaths based on NobBS, considering reporting delays. The pandemic peaked from May 17, 2020 to May 23, 2020 in the state of Maranhão and from May 3, 2020 to May 9, 2020 in the São Luís Island (Figure 2). Since then, the number of deaths has been decreasing, and economic activity has been gradually increasing whereas most restrictions, apart from banning mass gatherings and opening of public schools and universities, have been eased. Nearly three months since the beginning of the relaxation of social distancing, and despite increasing community mobility, reported deaths analyzed by date of occurrence remain low. 


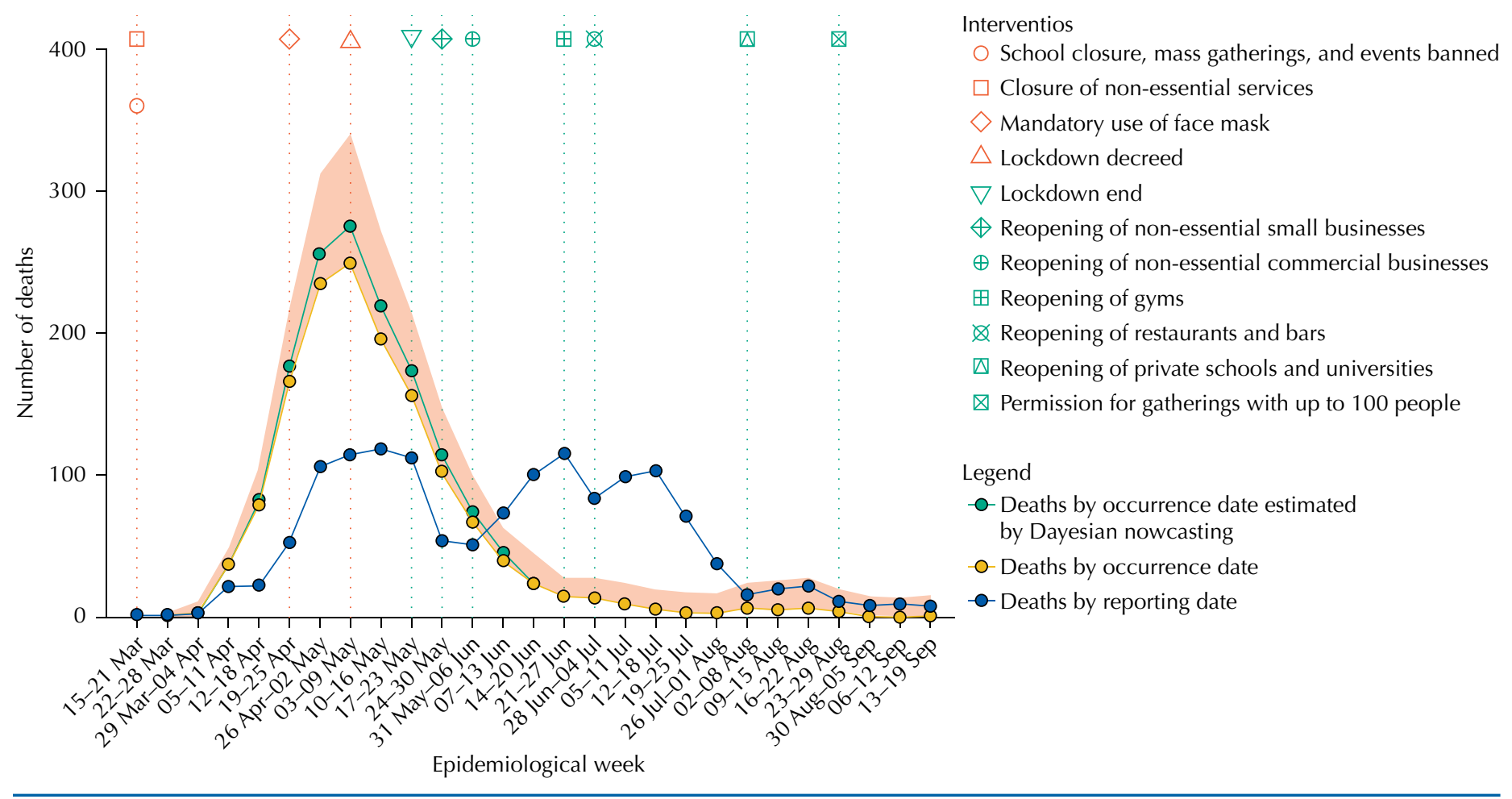

Figure 2. Weekly number of deaths by occurrence and reporting date, and estimated by Bayesian nowcasting from March 15 to September 19, São Luís Island, state of Maranhão, Brazil, 2020.

\section{DISCUSSION}

The population-based seroprevalence of SARS-CoV-2 in the state of Maranhão, Brazil was $40.4 \%$. We believe this is the first population-based study to report a prevalence rate in this range, for an area as big as Italy.

Over $90 \%$ of all infected people develop detectable antibodies against SARS-CoV-2 two weeks after infection ${ }^{29}$. Moreover, SARS-CoV-2 leads to robust memory T cell responses, suggesting that infection may at least prevent subsequent severe diseas $\mathrm{e}^{30}$. Furthermore, cross-reactivity between SARS-CoV-2 and coronaviruses that cause the common cold may elicit additional protection against infection ${ }^{31}$. Due to all these factors and based on a high seroprevalence of $40.4 \%$ achieved in the survey, our data suggests that the local herd immunity threshold may have been reached or might be reached soon, depending on the patterns of heterogeneity in susceptibility or exposure to infection ${ }^{7,8}$.

Nevertheless, the achievement of herd immunity will not be sustained if protection wanes ${ }^{32}$. Thus, durable immunity may not be attained before vaccination, and consequently, the population would remain susceptible to future recurrent outbreaks ${ }^{6}$.

In our study, we used the Elecsys ${ }^{\circ}$ Anti-SARS-CoV-2 electrochemiluminescence immunoassay, which presented a high specificity rate of $99.7 \%$ (95\% CI 99.2-100.0) and a positive predictive value (PPV) of $97.4 \%$ with a $10 \%$ seroprevalence rate ${ }^{33}$. Electrochemiluminescence immunoassays have been shown to present higher sensitivity than lateral flow immunoassays ${ }^{34}$. Some existing lateral flow immunoassays do not attain an ideal performance to be used in seroprevalence surveys, especially if they are used with finger-prick ${ }^{35}$. Therefore, since the test we used is more sensitive and specific, we could detect a higher percentage of people with antibodies against SARS-CoV-2 with few false-positive results. The distribution and percentage of self-reported symptoms among the infected in our survey were similar to what has been reported by others ${ }^{9,11,36}$, providing further evidence that a high false-positive rate in our study is unlikely. However, a negative Roche's Anti-SARS-CoV-2 serology assay does not rule out infection ${ }^{37}$. Moreover, sensitivity may decline over time due to seroreversion ${ }^{38}$. Therefore, we may have underascertained the true SARS-CoV-2 infection rate. 
We could not find evidence that infection rates differ by sex, age group, skin color, or income; however, given the survey's complex sampling design, our sample size lacked the statistical power to answer these questions. The infection rates were lower among those with tertiary education, in agreement with the São Paulo study ${ }^{39}$.

Infection rates were lower among mask wearers and among those that maintained social and physical distancing, suggesting that the use of face masks ${ }^{40}$ and social ${ }^{41,42}$ and physical distancing ${ }^{40}$ were necessary to prevent further infections and deaths. However, adherence to NPI to curb the COVID-19 pandemic tended to diminish.

Infected people were mostly symptomatic (62.2\%), and anosmia/hyposmia and ageusia/ dysgeusia were the two most reported symptoms. Most cases were mild. These findings are in agreement with recent studies ${ }^{19,36}$.

Our estimate of the IFR for the state of Maranhão was lower than the rate (0.71\%) estimated for Brazil ${ }^{9}$, the $0.90 \%$ estimate described for the $\mathrm{UK}^{36}$ and the combined estimate of $0.68 \%$ from a meta-analysis by Meyerowitz-Katz et al. $(2020)^{18}$, but more in line with the $0.24 \%$ combined estimate obtained by Ioannidis $(2020)^{10}$ and with the range of $0.30 \%-0.50 \%$ estimated by Bayesian Network Analysis ${ }^{16}$. Variations in IFR may be due to differences in the testing capacity, age structures, selective testing of high-risk populations, patterns of how deaths are attributed to COVID- $19^{6}$, and strain on the health services ${ }^{43}$. Therefore, IFR is likely to vary across populations. However, the IFR in Maranhão is one of the lowest reported to date ${ }^{10}$, even after considering reporting delays and excess deaths.

In our study, the case reporting rate was $4.5 \%$ for the state of Maranhão and 3.4\% for the São Luís Island, resulting in a ratio of the estimated infection to the reported cases as 22.2 for the state of Maranhão and 29.9 for the São Luís Island. These ratios were higher than the value of 10.3 reported for Brazil ${ }^{9}$.

Our study has strong points: it is population-based, had a high response rate of $77.4 \%$, and the use of a serum electrochemiluminescence immunoassay testing instead of a lateral flow immunoassay with finger-prick. There are some limitations: for some estimates, the confidence intervals were wide, and thus our power to detect statistically significant associations was lower than that desired; some population groups (men and people of working age) were underrepresented in our sample.

\section{REFERENCES}

1. Johns Hopkins University. COVID-19 Dashboard by the Center for Systems Science and Engineering (CSSE) at Johns Hopkins University. Baltimore, MD: CCSE; 2020 [cited 2020 Sept 21]. Available from: https://gisanddata.maps.arcgis.com/apps/ opsdashboard/index.html\#/bda7594740fd40299423467b48e9ecf6

2. The Lancet. COVID-19 in Brazil: "So what?" Lancet. 2020;395(10235):1461. https://doi.org/10.1016/S0140- 6736(20)31095-3

3. Candido DS, Claro IM, Jesus JG, Souza WM, Moreira FRR, Dellicour S, et al. Evolution and epidemic spread of SARS-CoV-2 in Brazil. Science. 2020;369(6508):1255-60. https://doi.org/10.1126/science.abd2161

4. Instituto Brasileiro de Geografia e Estatística. Projeção da população por sexo e idades simples, em $1^{\circ}$ de julho - 2010/2060. Rio de Janeiro: IBGE; 2018 [cited 2020 Aug 18]. Available from: ftp://ftp.ibge.gov.br/Projecao_da_Populacao/Projecao_da_Populacao_2018/projecoes_2018_ populacao_idade_simples_2010_2060.xls

5. Secretaria de Estado da Saúde do Maranhão. Bol Epidemiol COVID-19. 20 ago 2020 [cited 2020 Aug 21]. Available from: https://www.saude.ma.gov.br/wp-content/uploads/2020/08/BOLETIM-20-08.pdf

6. Randolph HE, Barreiro LB. Herd immunity: understanding COVID-19. Immunity. 2020;52(5):737-41. https://doi.org/10.1016/j.immuni.2020.04.012 
7. Aguas R, Corder RM, King JG, Gonçalves G, Ferreira MU, Gomes MGM. Herd immunity thresholds for SARS-CoV-2 estimated from unfolding epidemics. medRxiv [Preprint]. 2020 [posted 2020 Jul 24]. https://doi.org/10.1101/2020.07.23.20160762

8. Britton T, Ball F, Trapman P. A mathematical model reveals the influence of population heterogeneity on herd immunity to SARS-CoV-2. Science. 2020;369(6505):846-9. https://doi.org/10.1126/science.abc6810

9. Hallal PC, Hartwig FP, Horta BL, Victora GD, Silveira M, Struchiner C, et al. SARS-CoV-2 antibody prevalence in Brazil: results from two successive nationwide serological household surveys. Lancet Glob Heal. 2020;8(11):e1390-8. https://doi.org/10.1016/S2214-109X(20)30387-9

10. Ioannidis J. The infection fatality rate of COVID-19 inferred from seroprevalence data. medRxiv [Preprint]. 2020 [posted 2020 Jul 14]. https://doi.org/10.1101/2020.05.13.20101253

11. Pollán M, Pérez-Gómez B, Pastor-Barriuso R, Oteo M, Hernán MA, Pérez-Olmeda M, et al. Prevalence of SARS-CoV-2 in Spain (ENE-COVID): a nationwide, population-based seroepidemiological study. Lancet. 2020;396(10250):535-44. https://doi.org/10.1016/S0140-6736(20)31483-5

12. Rosenberg ES, Tesoriero JM, Rosenthal EM, Chung R, Barranco MA, Styer LM, et al. Cumulative incidence and diagnosis of SARS-CoV-2 infection in New York. Ann Epidemiol. 2020;48:23-29. e4. https://doi.org/10.1016/j.annepidem.2020.06.004

13. Tess BHC, Alves MCGP, Reinach F, Granato CFH, Rizzati EG, Pintão MC, et al. Inquérito domiciliar para monitorar a soroprevalência da infecção pelo vírus SARS-CoV-2 em adultos no município de São Paulo. São Paulo, SP: Projeto SoroEPI-MSP; 2020 [cited 2020 Aug 21]. Available from: https://0dea032c-2432-4690-b1e5-636d3cbeb2bf.filesusr.com/ugd/6b3408_901 41a5c289e43cfb75c2ce6408d299e.pdf

14. Buss LF, Prete Jr CA, Abrahim CMM, Mendrone Jr AM, Salomon T, Almeida-Neto C, et al. COVID-19 herd immunity in the Brazilian Amazon. medRxiv [Preprint]. 2020 [posted 2020 Sept 21]. https://doi.org/10.1101/2020.09.16.20194787

15. Russell TW, Hellewell J, Jarvis Cl, Zandvoort K, Abbott S, Ratnayake R, et al. Estimating the infection and case fatality ratio for coronavirus disease (COVID-19) using age-adjusted data from the outbreak on the Diamond Princess cruise ship, February 2020. Eurosurveillance. 2020;25(12):2000256. https://doi.org/10.2807/1560-7917.ES.2020.25.12.2000256

16. Verity R, Okell LC, Dorigatti I, Winskill P, Whittaker C, Imai N, et al. Estimates of the severity of coronavirus disease 2019: a model-based analysis. Lancet Infect Dis. 2020;20(6):669-77. https://doi.org/10.1016/S1473-3099(20)30243-7

17. Ing AJ, Cocks C, Green JP. COVID-19: in the footsteps of Ernest Shackleton. Thorax. 2020;75(8):693-4. https://doi.org/10.1136/thoraxjnl-2020-215091

18. Meyerowitz-Katz G, Merone L. A systematic review and meta-analysis of published research data on COVID-19 infection-fatality rates. Int J Infect Dis. 2020;101:138-48. https://doi.org/10.1016/j.ijid.2020.09.1464

19. Menezes AMB, Victora CG, Hartwig FP, Silveira MF, Horta BL, Barros AJD, et al. High prevalence of symptoms among Brazilian subjects with antibodies against 2 SARS-CoV-2: a nationwide household survey. medRxiv [Preprint]. 2020 [posted 2020 Aug 12]. https://doi.org/10.1101/2020.08.10.20171942

20. Byambasuren O, Cardona M, Bell K, Clark J, McLaws ML, Glasziou P. Estimating the extent of true asymptomatic COVID-19 and its potential for community transmission: systematic review and meta-analysis. medRxiv [Preprint]. 2020 [posted 2020 Sept 13] https://doi.org/10.1101/2020.05.10.20097543

21. Li R, Pei S, Chen B, Song Y, Zhang T, Yang W, et al. Substantial undocumented infection facilitates the rapid dissemination of novel coronavirus (SARS-CoV-2). Science. 2020;368(6490):489-93. https://doi.org/10.1126/science.abb3221

22. UNESCO. The International Standard Classification of Education ISCED 2011. Vol 5. Québec (CA): UNESCO Institute for Statistics; 2012 [cited 2020 Aug 21]. Available from: https://web.archive.org/web/20170106011231/https://uis.unesco.org/sites/default/files/ documents/international-standard-classification-of-education-isced-2011-en.pdf

23. Travassos C, Williams DR. The concept and measurement of race and their relationship to public health: a review focused on Brazil and the United States. Cad Saude Publica. 2004;20(3):660-78. https://doi.org/10.1590/S0102-311X2004000300003 
24. Muench $\mathrm{P}$, Jochum $\mathrm{S}$, Wenderoth $\mathrm{V}$, Ofenloch-Haehnle B, Hombach M, Strobl M, et al. Development and validation of the Elecsys Anti-SARS-CoV-2 Immunoassay as a highly specific tool for determining past exposure to SARS-CoV-2. J Clin Microbiol. 2020;58(10):e01694-20. https://doi.org/10.1128/JCM.01694-20

25. McGough SF, Johansson MA, Lipsitch M, Menzies NA. Nowcasting by Bayesian Smoothing: a flexible, generalizable model for real-time epidemic tracking. PLoS Comput Biol. 2020;16(4):e1007735. https://doi.org/10.1371/journal.pcbi.1007735

26. Conselho Nacional de Secretários de Saúde. Painel de análise do excesso de mortalidade por causas naturais no Brasil em 2020. Brasília, DF: CONASS; 2020 [cited 2020 Sept 21]. Available from: https://www.conass.org.br/indicadores-de-obitos-por-causas-naturais/

27. Marinho F, Torrens A, Teixeira R, França E, Nogales AM, Xavier $D$, et al. Excess mortality in Brazil: detailed description of trends in mortality during the COVID-19 pandemic. New York: Vital Strategies; 2020 [cited 2020 Aug 21]. Available from: https://www.vitalstrategies.org/wp-content/uploads/RMS_ExcessMortality_BR_Report-English.pdf

28. Pastor-Barriuso R, Pérez-Gómez B, Hernán MA, Pérez-Olmeda M, Yotti R, Oteo J, et al. SARS-CoV-2 infection fatality risk in a nationwide seroepidemiological study. medRxiv [Preprint]. 2020 [posted 2020 Aug 7]. https://doi.org/10.1101/2020.08.06.20169722

29. Health Information and Quality Authority. Evidence summary of the immune response following infection with SARS- CoV-2 or other human coronaviruses. Dublin (IRL): HIQA; 2020 [cited 2020 Aug 21]. Available from: https://www.hiqa.ie/sites/default/files/2020-06/Evidencesummary_SARS-CoV-2-immune-response.pdf

30. Sekine T, Perez-Potti A, Rivera-Ballesteros O, Stralin K, Gorin JB, Olsson A, et al. Robust T cell immunity in convalescent individuals with asymptomatic or mild COVID-19. Cell. 2020;183(1):158-68.e14. https://doi.org/10.1016/j.cell.2020.08.017

31. Grifoni A, Weiskopf D, Ramirez SI, Mateus J, Dan JM, Moderbacher CR, et al. Targets of T Cell responses to SARS-CoV-2 Coronavirus in humans with COVID-19 disease and unexposed individuals. Cell. 2020;181(7):1489-1501.e15. https://doi.org/10.1016/j.cell.2020.05.015

32. Long QX, Tang XJ, Shi QL, Deng HJ, Yuan J, HU JL, et al. Clinical and immunological assessment of asymptomatic SARS-CoV-2 infections. Nat Med. 2020;26(8):1200-4. https://doi.org/10.1038/s41591-020-0965-6

33. Perkmann T, Perkmann-Nagele N, Breyer MK, Breyer-Kohansal-R, Bugghuber OC, Hartl S, et al. Side by side comparison of three fully automated SARS-CoV-2 antibody assays with a focus on specificity. Clin Chem. 2020 Aug 10; hvaa198. https://doi.org/10.1093/clinchem/hvaa198. Epub ahead of print

34. Bastos ML, Tavaziva G, Abidi SK, Campbell JR, Haraoui LP, Johnston JC, et al. Diagnostic accuracy of serological tests for covid-19: systematic review and meta-analysis. BMJ. 2020;370:m2516. https://doi.org/10.1136/bmj.m2516

35. Flower B, Brown JC, Simmons B, Moshe M, Frise R, Penn R, et al. Clinical and laboratory evaluation of SARS-CoV-2 lateral flow assays for use in a national COVID-19 seroprevalence survey. Thorax. 2020 Aug 12;thoraxjnl-2020-215732. https://doi.org/10.1136/thoraxjnl-2020-215732. Epub ahead of print.

36. Ward H, Atchison CJ, Whitaker M, Ainslie KEC, Elliott JE, Okell LC, et al. Antibody prevalence for SARS-CoV-2 in England following the first peak of the pandemic: REACT2 study in 100,000 adults. medRxiv [Preprint]. 2020 [posted 2020 Aug 21]. https://doi.org/10.1101/2020.08.12.20173690

37. Mahase E. Covid-19: two antibody tests are "highly specific" but vary in sensitivity, evaluations find. BMJ. 2020;369;m2066. https://doi.org/10.1136/bmj.m2066

38. Muecksch F, Wise H, Batchelor B, Squires M, Semple E, Richardson C, et al. Longitudinal analysis of clinical serology assay performance and neutralising antibody levels in COVID19 convalescents. medRxiv [Preprint]. 2020 [posted 2020 Aug 6]. https://doi.org/10.1101/2020.08.05.20169128

39. Tess BH, Granato CFH, Alves MCGP, Pintão MC, Rizzatti E, Nunes $M C$, et al. SARS-CoV-2 seroprevalence in the municipality of São Paulo, Brazil, ten weeks after the first reported case. medRxiv [Preprint]. 2020 [posted 2020 June 29,]. https://doi.org/10.1101/2020.06.29.20142331

40. Chu DK, AkI EA, Duda S, Solo K, Yaacoub S, Schünemann HJ, et al. Physical distancing, face masks, and eye protection to prevent person-to-person transmission of SARS-CoV-2 and COVID-19: a systematic review and meta-analysis. Lancet. 2020;395(10242):1973-87. https://doi.org/10.1016/S0140-6736(20)31142-9 
41. Flaxman S, Mishra S, Gandy A, Unwin HJT, Mellan TA, Coupland H, et al. Estimating the effects of non-pharmaceutical interventions on COVID-19 in Europe. Nature. 2020;584(7820):257-61. https://doi.org/10.1038/s41586-020-2405-7

42. Walker PGT, Whittaker C, Watson OJ, Baguelin M, Winskill P, Hamlet A, et al. The impact of COVID-19 and strategies for mitigation and suppression in low- and middle-income countries. Science. 2020;369(6502):413-22. https://doi.org/10.1126/science.abc0035

43. Kenyon C. COVID-19 infection fatality rate associated with incidence: a population-level analysis of 19 Spanish autonomous communities. Biology (Basel). 2020;9(6):128. https://doi.org/10.3390/biology9060128

Funding: Secretaria de Saúde do Estado do Maranhão and Coordenação de Aperfeiçoamento de Pessoal de Nível Superior (Capes - finance code 001, Brasil)

Authors' Contribution: Conception and design of the work, acquisition, analysis, and interpretation of the data, and writing of the manuscript: AAMS, LGLN, CMPSA, LMC, MLBMB, AKDBF, BBW, BLCAO, CAC, EBAFT, EASN, JFLJ, MAGC, RCSQ, VAC, VMFS, MTSBA and MAS. Acquisition and analysis of the data: BFS, SSC and LMSC. Revised and approved the final version of the article, and take public responsibility for its content: AAMS, LGLN, CMPSA, LMC, MLBMB, AKDBF, BBW, BLCAO, CAC, EBAFT, EASN, JFLJ, BFS, SSC, LMSC, MAGC, RCSQ, VAC, VMFS, MTSBA and MAS.

Conflict of Interest: The authors declare no conflict of interest. 